\title{
MI (2-methyl-4-isothiazolin-3-one) contained in detergents is not detectable in machine washed textiles
}

Maja A. Hofmann ${ }^{1,2}$, Ana Giménez-Arnau ${ }^{3}$, Werner Aberer ${ }^{4}$, Carsten Bindslev-Jensen ${ }^{2}$ and Torsten Zuberbier ${ }^{1 *}$ (D)

\begin{abstract}
Background: European legislation has banned the preservative methylisothiazolinone (MI) from inclusion in leaveon cosmetics. However, the risk for allergic reactions depends on exposure. The aim of this study was to determine the risk of $\mathrm{Ml}$ in laundry detergents for household machine washing.

Methods: Different formulations of laundry detergents with commercial Ml levels, up to one thousand ppm were used and three different types of clothes were washed in a normal household machine setting one time and 10 times. The level of MI was measured by HPLC.

Results: While Ml could be retrieved in the positive control of clothes drenched with washing powder but not washed afterwards, Ml could not be detected in any specimen of clothes washed under household conditions. The detection limit was 0.5 ppm.

Conclusion: It is important to discuss the difference of risk and hazard. While Ml clearly is a high hazard as a strong contact allergen, the risk depends on exposure. Regarding the risk of exposure levels for the consumer to Ml in clothes it can be stated that the use of MI in laundry detergents is safe for the consumer if these products are used according to the instructions in the normal household setting machine wash.
\end{abstract}

Keywords: MI, Laundry detergent, Preservative, Contact allergy

\section{Introduction}

Methylisothiazolinone (MI) belongs to the group of isothiazolinones, together with methylchloroisothiazolinone (MCI) and benzisothiazolinone (BIT). MI is often used alone, but it is also common to use MCI and MI in combination as preservatives, firstly introduced in the 1980s in a fixed 3:1 (MCI/MI) combination for industrial use.

As $\mathrm{MCI} / \mathrm{MI}$ have antimicrobial activities against gram + and gram - bacteria, moulds and yeasts, they have been used as preservatives in cosmetic products and chemical products, such as in paints.

Contact allergy to methylisothiazolinone (MI) was commonly attributed to the usage in cosmetics but $\mathrm{MI}$ is

\footnotetext{
*Correspondence: torsten.zuberbier@charite.de

1 Department of Dermatology and Allergy, Charité-Universitätsmedizin Berlin, Charitéplatz 1, 10117 Berlin, Germany

Full list of author information is available at the end of the article
}

also a common preservative in household detergents and water-based paint [1].

There is an ongoing important interest in MI as a preservative as the prevalence of sensitizations to $\mathrm{MCI} / \mathrm{MI}$ and $\mathrm{MI}$ increased during the past years in Europe. In Germany, the sensitization rate to $\mathrm{MCI} / \mathrm{MI}$ increased from $2.3 \%$ in 2009 to $3.9 \%$ in 2011 [2].

Up until the 1990s MI was only used as a preservative in cosmetics, in a concentration of $15 \mathrm{ppm}$ in Europe, with a contact sensitization rate of about $2 \%$ with a stable trend. After the 2000, MI was introduced as a preservative also in non-cosmetics, chemical products (paint, inks, lacquers, varnishes, and cooling fluid). Firstly, occupational contact sensitizations to $\mathrm{MCI} / \mathrm{MI}$ or MI were reported among painters and paint factory workers in particular [3]. MI was also allowed in cosmetic products up to a concentration of $100 \mathrm{ppm}$ (Cosmetic Directive 2005/42/EC), as the antimicrobial effect is somewhat 
weaker than the MI/MCI combination, upon which an increase of non-occupational sensitization was noted [4].

As MI is volatile and can evaporate, it can also cause airborne contact dermatitis or asthmatic symptoms [5]. It was shown to be one of the most important contact allergens associated with airborne contact dermatitis such as components of epoxy resin systems and compositae [6].

Due to the increased sensitization rates to MI, the Scientific Committee on Consumer Safety of the European Commission (SCCS) has now banned this preservative from Leave-on cosmetics eventhough the range of the cosmetics are wide; including hair cosmetics, facial cosmetics, deodorants, sunscreens and wet wipes (baby wipes, moist tissues, moist toilet paper).

On the other hand, it should be noted that isothiazolinone derivates are used in the production of clothes and could be an independent source, although as of yet only occupational reactions to the preservative during the production have been described. No systematic review exists if remnants are found in the clothes. Furthermore, a combination of 5-chloro-2-methyl-4-isothiazolin-3-one and 2-methyl-4-isothiazolin-3-one was described to lead to occupational dermatitis in the nylon production and in spin finish $[7,8]$. In both cases MI was used as a preservative not alone but in combination with methylchloroisothiazolinone. A further report has been published regarding this preservative combination called Acticide SPX, a $1.5 \%$ mixture of 5-chloro-2-methyl1-4-isothiazolinone-3-one and 2-methyl-4-isothiazolin3-one, flax spinners were sensitized by this combination occupationally [9].

The use of MI in rinse-off products (shampoos) has been limited to $15 \mathrm{ppm}$. As preservatives are necessary in many consumer products used in daily life, it is of high interest that alternatives should replace well-known preservatives without knowing the risk of their sensitization potential in the different product groups.

The aim of this study was to determine the risk of the consumer through using MI in laundry detergents based on the remnant of the preservative in the washed clothes. As of yet, no study exists if there is a risk that MI residues remain in washed clothes.

\section{Materials and methods}

2-Methyl-4-isothiazolin-3-one (MI, purity $\geq 99 \%$ ) was purchased from Fluka/Sigma (Buchs, Switzerland). Methanol LiChrosolv Gradient Grade for sample preparation and liquid chromatography was purchased from Merck (Darmstadt, Germany). Deionized water was produced via Merck-Millipore Milli-Q Avantage A10 facility. Ortho-phosphoric acid (p.A. 85\%) and hydrochloric acid (p.A. 37\%) were purchased from VWR International GmbH (Darmstadt, Germany). Disposable syringe filters
(SRP-15 $0.45 \mu \mathrm{m}$ ) were purchased from Sartorius (Goettingen, Germany).

Textile sample contained of wkf 10A (standard cotton), wfK 20A (polyester/cotton), wfK30 (polyester fibre), http://www.testgewebe.de/en/products/ reference-and-standard-fabrics/.

As washing agent a commercially available universal detergent (Italian market) was used. Different concentrations of preservatives were added to this detergent: no preservative, $0.11 \%$ Acticide MBR1, 1.1\% Acticide MBR1 (containing 9\% of MI).

The washing process was performed with a Miele Novotronic W1734 household washing machine. A colour program with $20{ }^{\circ} \mathrm{C}$ with $3.5 \mathrm{~kg}$ laundry and $75 \mathrm{ml}$ of washing agent was used. The textile samples were mixed with normal dirty clothes. Normal urban tap water was used and 4 SBS 2004 as ballast load were added (http://www.testgewebe.de/en/products/sbl/ sbl-2004/).

The textile samples were dried on the line and washed either one time or 10 times. In the case of 10 times, the above-mentioned washing process was repeated the same way.

As positive control the same Textile samples of wkf 10A (cotton wool), wfK 20A (polyester fibre, cotton wool), wfK30 (polyester fibre) were drenched with the three washing powders with different concentrations of MI but not washed afterwards.

Approximately $2 \mathrm{~g}$ of each textile sample were cut into pieces of $1-2 \mathrm{~cm}^{2}$ and transferred into a glass vessel. Afterwards, $25 \mathrm{~mL}$ of a mixture containing $95 \%$ of diluted o-phosphoric acid $(0.025 \%)$ and $5 \%$ of methanol $(\mathrm{V} / \mathrm{V})$ were added. The samples were extracted for 10 min using an ultrasonic bath. After extraction, an aliquot was filtered and used for HPLC analysis. The HPLC system was calibrated via MI calibration solutions ranging from $12 \mu \mathrm{g} / \mathrm{L}$ to $2.4 \mathrm{mg} / \mathrm{L}$. For that purpose, the standard substance MI was first dissolved in methanol (30 $\mathrm{mg}$ in $100 \mathrm{~mL}$ ) and afterwards diluted appropriately using a mixture containing $95 \%$ of diluted o-phosphoric acid $(0.025 \%)$ and $5 \%$ of methanol $(\mathrm{V} / \mathrm{V})$.

The HPLC instrument was supplied by Waters (Milford, USA) and consisted of the modules Acquity UPLC ${ }^{\mathrm{TM}}$ BSM, Acquity UPLC ${ }^{\mathrm{TM}}$ SM, Acquity UPLC ${ }^{\mathrm{TM}} \mathrm{CM}$ and Acquity UPLC ${ }^{\mathrm{TM}}$ PDA. For chromatographic separation, a Waters Acquity UPLC ${ }^{\mathrm{TM}} \mathrm{RP} 18$ column $(2.1 \times 100 \mathrm{~mm})$ was used, maintained at $40{ }^{\circ} \mathrm{C}$ in the column compartment. The injection volume was set to $10 \mu \mathrm{L}$. Gradient elution was performed using $0.25 \%$ o-phosporic acid (eluent A) and methanol (eluent B) at a flow rate of $0.4 \mathrm{~mL} / \mathrm{min}$. The analyte MI was detected at a wavelength of $274 \mathrm{~nm}$ and quantified using external standard calibration. 


\section{Results}

In the first step, it could be shown that 2-methyl-4-isothiazolin-3-one can be separated from interfering matrix compounds by chromatographic analysis. The analysis was run through with replicates of a cotton fabric (CO), washed one time and washed 10 times. The UV-spectrum of MI is shown in Fig. 1. Figure 2 shows the spiked washed cotton without and with $0.9 \mu \mathrm{g} / \mathrm{g}$ MI. It could be clearly shown that MI can be measured chromatographically in cotton wool samples.

For calibration, it could be shown that the calibration curve for 2-methyl-4-isothiazolin-3-one is linear in the calibration range of interest $(R>0.9999)$. System precision was determined by a sixfold injection of a calibration standard. The relative standard deviation (RSD) for 2-methyl-4-isothiazolin-3-one was determined to be $0.5 \%$.
For determination of method precision, six replicates each of a cotton fabric (Co), polyester fabric and blended fabric (cotton with polyester) were spiked with 18 and $1.8 \mu \mathrm{g}$ 2-methyl-4-isothiazolin-3-one. After sample analysis, a relative standard deviation of $1.0-1.4 \%$ was determined for the $18 \mu \mathrm{g}$ spiking level, and $6-10 \%$ for the $1.8 \mu \mathrm{g}$ spiking level. For determination of accuracy, the values obtained for method precision were used. A recovery rate of $97.9-100 \%$ was determined for the $18 \mu \mathrm{g}$ spiking level, and $72.3-88.7 \%$ for the $1.8 \mu \mathrm{g}$ spiking level.

The methodology has a detection limit of $0.098 \mu \mathrm{g}$ of 2-methyl-4-isothiazolin-3-one related to $25 \mathrm{~mL}$ of extraction solution. Due to the sample preparation, this is equivalent to $0.05 \mu \mathrm{g} / \mathrm{g}$ related to the weighed fabric sample.

In experiments with machine washed cloth it could be shown that MI could not be detected either in

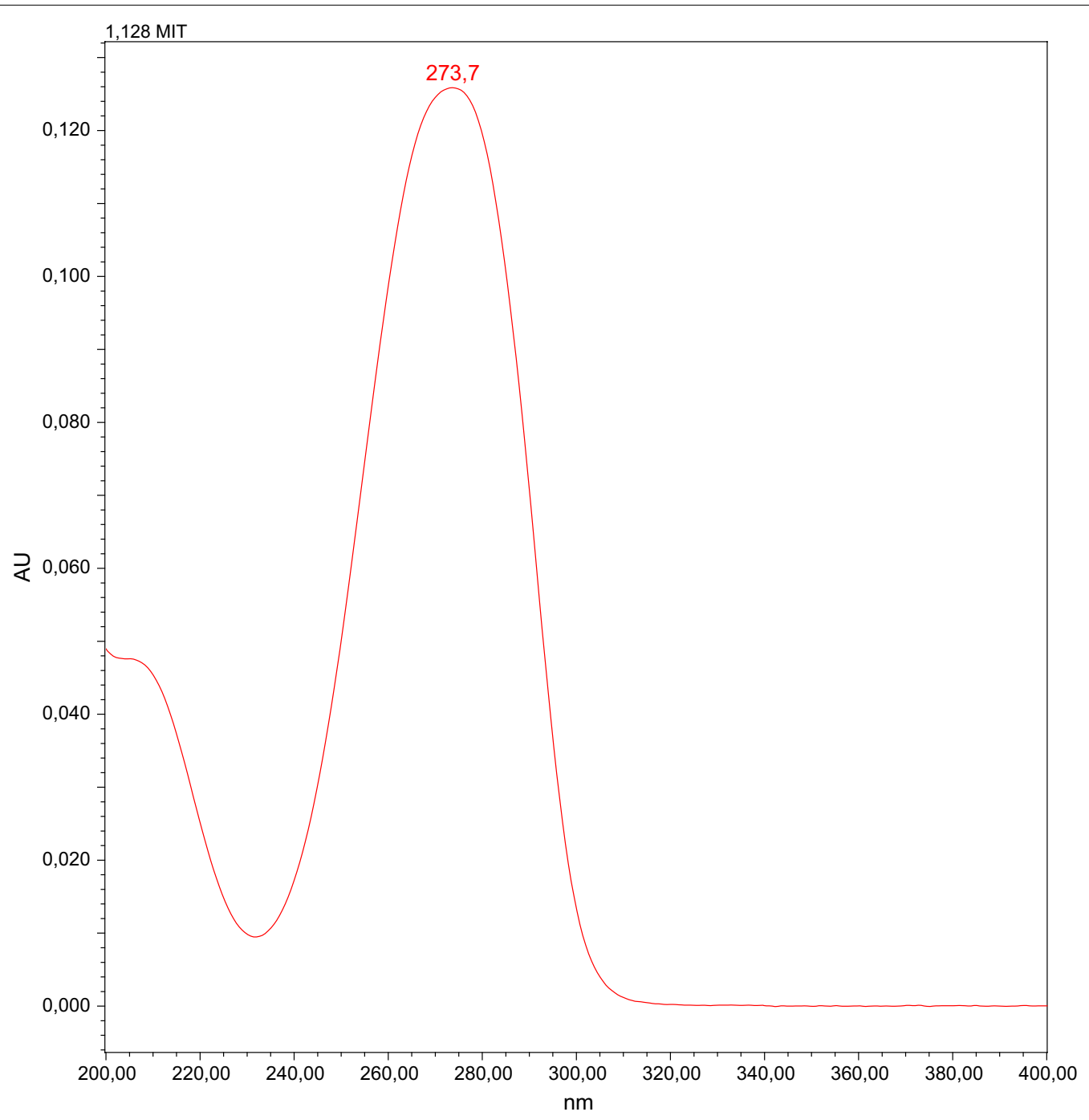

Fig. 1 UV-spectrum of MI. Chromatographically analysis of Ml, the maximum peak is seen at $273.3 \mathrm{~nm}$ 


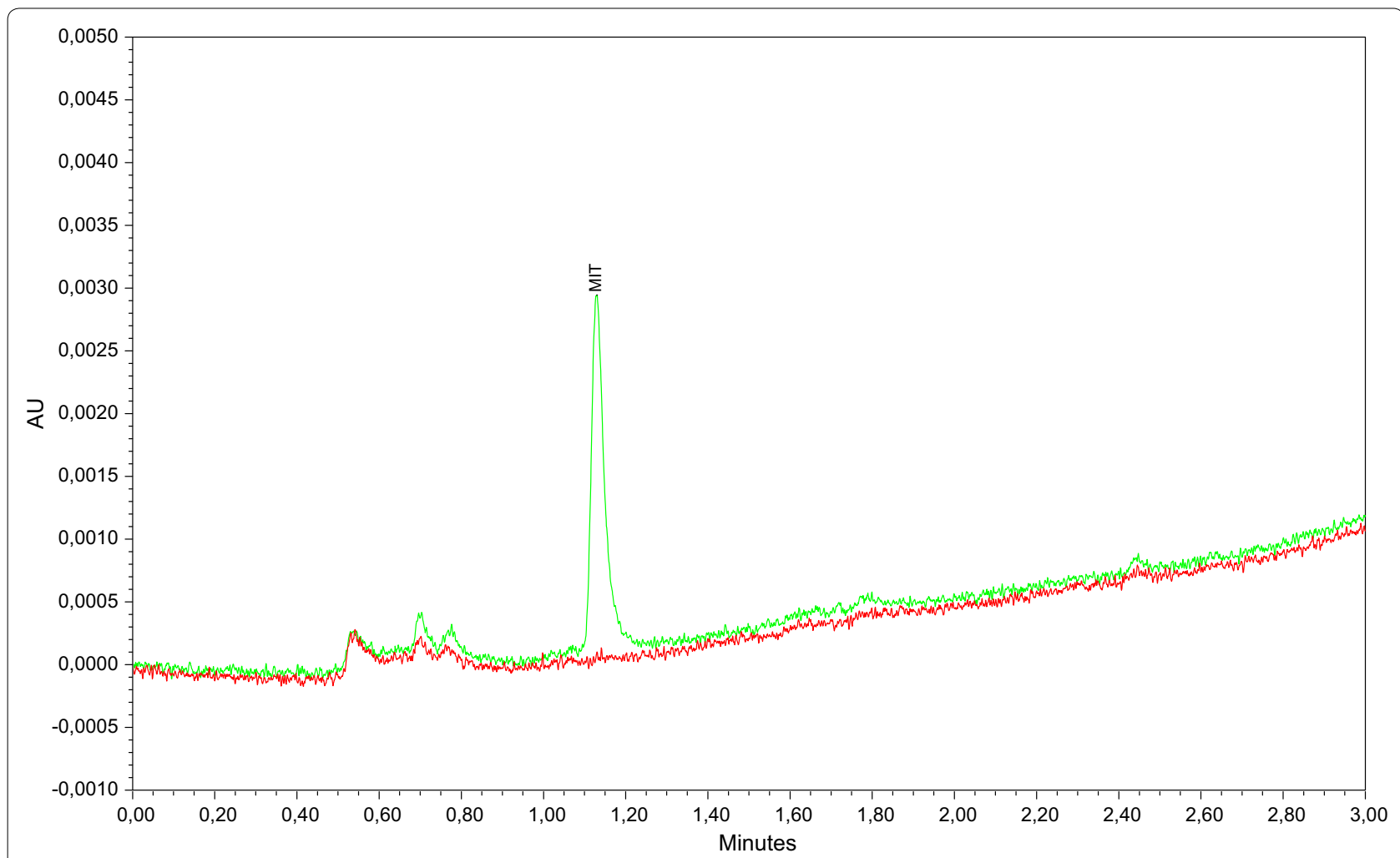

Fig. 2 Chromatogram overlay of washed cotton swatch without Ml and with MI. Proof of concept, validation of methodology. Washed cotton without MI (red) and with $0.9 \mu \mathrm{g} / \mathrm{g} \mathrm{MI}$ (green), Ml can be measured chromatographically in cotton wool samples

cotton wool samples, or in polyester fibre or in polyester fibre/cotton wool samples after washing (Table 1). Furthermore there was no difference in the detection of MI regarding one washing or ten washes. This shows that there is no enrichment of potential residues after repeated washing. Even after using an artificially MI enriched detergent containing 1000 ppm MI which is far above the level found in commercialized products, there was no detection of $\mathrm{MI}$ in the chromatogram, after 1 wash or 10 washes.

\section{Discussion}

The increasing incidence of MI contact allergy is evident and is alarming.
In early years, sensitization levels were stable as MI was only used in cosmetics in combination with MCI and a low concentration up to $15 \mathrm{ppm}$. However, after the year 2000, the sensitization rate started to rise after published expert opinion suggesting that 100 ppm was safe. Furthermore, MI was used more repeatedly for occupational purposes due to workplace use of hygiene (healthcare) and beauty products (hairdressers and beauticians) together with water-based paints and other aqueous solutions such as cutting fluids [10]. Until now, MI has been used in a wide range of cosmetic products as well as Rinse-off and Leave-on cosmetics. Sensitization cases were attributed to Leave-on body products, like creams or lotions [11] and nowadays there is an increasing

Table 1 MI-residue analysis of laundry fabrics after washing

\begin{tabular}{|c|c|c|c|c|c|c|c|}
\hline \multirow[t]{2}{*}{ Products measured } & & \multicolumn{2}{|l|}{ PES washed } & \multicolumn{2}{|l|}{ Co/PES washed } & \multicolumn{2}{|l|}{ Co washed } \\
\hline & & $1 x$ & $10 x$ & $1 x$ & $10 x$ & $1 x$ & $10 x$ \\
\hline w/o preservation (WLHUL1604500) & $<1 \mathrm{ppm}$ & Not detectable & Not detectable & Not detectable & Not detectable & Not detectable & Not de \\
\hline 100 ppm MI (WLHUL1604600) & 100 ppm & Not detectable & Not detectable & Not detectable & Not detectable & Not detectable & Not detectable \\
\hline 1000 ppm MI (WLHUL1604700) & 1000 ppm & Not detectable & Not detectable & Not detectable & Not detectable & Not detectable & Not detectable \\
\hline
\end{tabular}

MI detection in PES, Co/PES and CO washed one time or ten times in different MI concentration (<1, 100 and 1000 ppm). MI, 2-methyl-4-isothiazolin-3-one; Co, cotton fabric; PES, polyester fabric; co/PES, blended fabric (cotton with polyester), detection limit $<0.05 \mathrm{ppm}$ 
number of reports induced by rinse-off products containing MI [12-14]. Therefore, MI was banned as a preservative in leave-on/on products in 2013. It is also known that in patients with sensitization to MI, the usage of rinse-off products can elicit contact allergic symptoms in dosages of $100 \mathrm{ppm}$ and less frequently also in lower dosages of $50 \mathrm{ppm}$ [12] but the overall frequency is less high than seen with leave-on products.

Warburton et al. [15] tested with very high concentrations of $2000 \mathrm{ppm}(0.2 \%$ as used in the British standard $)$ and could only identify 3 patients who had developed eczema between July and December 2014, attributing it to rinse-off products.

This shows that the potent allergenic potential of MI has to be seen in the context of true exposure in different products and especially in products outside the cosmetics range such as laundry detergents. The data of this study revealed two important findings regarding this point. The first finding is that MI in laundry detergents is completely washed out after using a normal household machine washing. This is important regarding for both a NOEL in sensitizing and eliciting contact allergic reactions to MI. With the detection level of $0.05 \mathrm{ppm}$ this is the case.

Even laundry detergents spiked with artificially high concentrations of MI up to $1000 \mathrm{ppm}$ can be used safely as there are no detectable levels of MI in the washed clothes. This information is important for the consumer as the concentration of MI is not labeled on the package and in addition is still safe in case of overdosing the detergent [7-9].

Currently we notice that the discussion about MI has become very emotional even among scientists and is also incriminating the whole chemical group of isothiazolinones, especially benzisothiazolinone (BIT) and octylisothiazolinone (OIT). But sensitization to MI does not show an immunological cross reaction to BIT and OIT [16]. We hope that our findings help to start a more rational debate as consumer products in many fields are still depending on the use of preservatives to ensure microbiological safety for the consumer.

\section{Conclusion}

It is important to discuss the safety of all ingredients in household products which may cause contact allergy but it is also important to have an evidence based rational debate. As for the risk of exposure levels for the consumer to MI in clothes, it can be stated that the use of MI in laundry detergents is safe for the consumer if these products are used according to the instructions in a normal household setting machine wash as MI is not detected in washed clothes.
Furthermore, it is important to see a potential contact allergen in different ways. A potential contact allergen as a preservative should not be banned totally but has to be seen in context of its usage.

\section{Abbreviations}

BIT: benzisothiazolinone; HPLC: high performance liquid chromatography; MI: methylisothiazolinone; $\mathrm{MCl}$ : methylchloroisothiazolinone; NOEL: no observed effects level; OIT: octylisothiazolinone; RSD: relative standard deviation; SCCS: Scientific Committee on Consumer Safety of the European Commission.

\section{Author's contributions}

MAH Data analysis and interpretation, Drafting, the article, Revision of the article, Final approval of the version to be published. AG Critical revision of the article. CB Critical revision of the article. WA Data analysis and interpretation, Critical revision of the article, Final approval of the version to be published. TZ Conception/Design of the work, Data collection, Data analysis and interpretation, Critical revision of the article. All authors read and approved the final manuscript.

Maja A. Hofmann and Torsten Zuberbier: Corporate member of Freie Universität Berlin, Humboldt-Universität zu Berlin, and Berlin Institute of Health, Berlin, Germany.

\section{Author details}

${ }^{1}$ Department of Dermatology and Allergy, Charité-Universitätsmedizin Berlin, Charitéplatz 1, 10117 Berlin, Germany. ${ }^{2}$ Department of Dermatology and Allergy Center, Odense Research Center for Anaphylaxis (ORCA), Odense University Hospital, University of Southern Denmark, 5000 Odense C, Denmark. ${ }^{3}$ Department of Dermatology, Hospital del Mar, Universitat Autònoma, Barcelona, Spain. ${ }^{4}$ Department of Dermatology and Venerology, Medical University of Graz, Auenbruggerplatz 8, 8036 Graz, Austria.

\section{Acknowledgements}

The study was supported by the European Centre for Allergy Research Foundation. A request was sent out to perform the analytics to three commercial labs (Wfk Cleaning Technology Institute e.V., Krefeld, Germany; Hohenstein Institute, Bönnigheim, Germany; VDE -the Association for Electrical, Electronic \& Information Technologies, Frankfurt, Germany; TüV Rheinland, Germany). Only Henkel lab, Düsseldorf, Germany offered to perform the tests but also here the technology to measure MI had to be established and the initially offered payment for the tests was therefore generously waived.

\section{Competing interests}

Maja A. Hofmann has participated in clinical and experimental studies, symposia or advisory boards funded by Allmirall Hermal, Asclepion, Bayer HealthCare, Candela, Galderma, Glaxo Smith Kline, IFC Dermatologie, Laserwelt, Leo Pharma, Loréal, LTB Berlin, Novartis, Novoxel, Pierre Fabre Dermatokosmetics, Sanofi Aventis, S \& V Technologies. Ana Giménez-Arnau has received institutional funding for research and/or honoria for lectures and/or consulting Almirall, Bayer Health Care, FAES Uriach Pharma, Genentech, GSK Novartis, FAES, LEO- PHARMA, Menarini, Merck MSD, Uriach Pharma. Torsten Zuberbier has received institutional funding for research and/or honoria for lectures and/or consulting ALK, Almirall, Abbvie, Astellas, Bayer Health Care, Bencard, Berlin Chemie, FAES, HAL, Henkel, Kryolan, Leti, Meda, Menarini, Merck, MSD, Novartis, Pharmasquire, Quintiles, Serono, Stallergenes, Takeda, Teva and UCB. Additionally, he is a member of ARIANWHO, DGAKI, ECARF, GA²LEN and WAO.

\section{Availability of data and materials}

The datasets used and/or analysed during the current study are available from the corresponding author upon reasonable request.

\section{Consent for publication \\ Not applicable.}

Ethics approval and consent to participate Not applicable. 


\section{Funding}

The study was supported by the European Centre for Allergy Research Foundation.

\section{Publisher's Note}

Springer Nature remains neutral with regard to jurisdictional claims in published maps and institutional affiliations.

Received: 22 September 2017 Accepted: 15 December 2017 Published online: 05 January 2018

\section{References}

1. Magnano M, Silvani S, Vincenzi C, Nino M, Tosti A. Contact allergens and irritants in household washing and cleaning products. Contact Dermat. 2009;61:337-41.

2. Geier J, Lessmann $H$, Schnuch $A$, Uter W. Recent increase in allergic reactions to methylchloroisothiazolinone/methylisothiazolinone: is methylisothiazolinone the culprit? Contact Dermat. 2012;67:334-41.

3. Schwensen JF, Lundov MD, Bossi R, Banerjee P, Gimenez-Arnau E, Lepoittevin JP, Liden C, Uter W, Yazar K, White IR, Johansen JD. Methylisothiazolinone and benzisothiazolinone are widely used in paint: a multicentre study of paints from five European countries. Contact Dermat. 2015;72:127-38.

4. Urwin R, Wilkinson M. Methylchloroisothiazolinone and methylisothiazolinone contact allergy: a new'epidemic.' Contact Dermat. 2013:68:253-5.

5. Lundov MD, Zachariae C, Menne T, Johansen JD. Airborne exposure to preservative methylisothiazolinone causes severe allergic reactions. BMJ. 2012;345:e8221.

6. Breuer K, Uter W, Geier J. Epidemiological data on airborne contact dermatitis—results of the IVDK. Contact Dermat. 2015;73:239-47.
7. Valsecchi R, Leghissa P, Piazzolla S, Cainelli T, Seghizzi P. Occupational dermatitis from isothiazolinones in the nylon production. Dermatology. 1993;187:109-11.

8. Podmore P. Occupational allergic contact dermatitis from both 2-bromo2-nitropropane-1,3-diol and methylchloroisothiazolinone plus methylisothiazolinone in spin finish. Contact Dermat. 2000;43:45.

9. Podmore P. An epidemic of isothiazolinone sensitization in a flax spinning mill. Contact Dermat. 1998;38:165-6.

10. Latheef F, Wilkinson SM. Methylisothiazolinone outbreak in the European Union. Curr Opin Allergy Clin Immunol. 2015;15:461-6.

11. Ali FR, Shepherd EL, Yell LC, Buckley DA, Williams JD. Escalating methylisothiazolinone/methylchloroisothiazolinone allergy probably attributable to methylisothiazolinone in leave-on body cosmetics. Contact Dermat. 2014;70:316-7.

12. Yazar K, Lundov MD, Faurschou A, Matura M, Boman A, Johansen JD, Liden C. Methylisothiazolinone in rinse-off products causes allergic contact dermatitis: a repeated open-application study. Br J Dermatol. 2015:173:115-22

13. Scientific Committee of Consumer S-S, Gimenez-Arnau AM. Opinion of the Scientific Committee on Consumer safety (SCCS) - opinion on the safety of the use of Methylisothiazolinone (MI) (P94), in cosmetic products (sensitisation only). Regul Toxicol Pharmacol. 2016;76:211-2.

14. Aerts $\mathrm{O}$, Goossens A, Giordano-Labadie F. Contact allergy caused by methylisothiazolinone: the Belgian-French experience. Eur J Dermatol. 2015;25:228-33.

15. Warburton $\mathrm{KL}$, Wilkinson M. Contact allergy to methylisothiazolinone: Has there been any change? Experience of a UK centre. Contact Dermat. 2015;72:398-400

16. Geier J, Lessmann H, Schnuch A, Uter W. Concomitant reactivity to methylisothiazolinone, benzisothiazolinone, and octylisothiazolinone. International Network of Departments of Dermatology data, 2009-2013. Contact Dermat. 2015;72:337-9.

\section{Submit your next manuscript to BioMed Central and we will help you at every step:}

- We accept pre-submission inquiries

- Our selector tool helps you to find the most relevant journal

- We provide round the clock customer support

- Convenient online submission

- Thorough peer review

- Inclusion in PubMed and all major indexing services

- Maximum visibility for your research

Submit your manuscript at www.biomedcentral.com/submit
() Biomed Central 